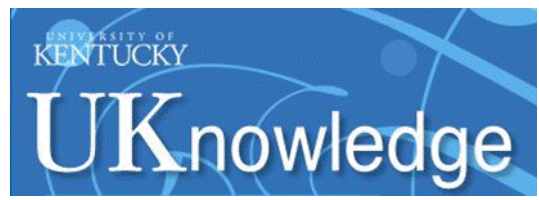

University of Kentucky

UKnowledge

Power and Energy Institute of Kentucky Faculty Publications

$10-2018$

\title{
Simulation Studies for a Multi-MW Hybrid Wind-Solar PV System for Desalination Plants
}

\author{
Vandana Rallabandi \\ University of Kentucky, vandana.rallabandi@uky.edu \\ Nasser Alawhali \\ University of Kentucky, nasser.alawhali@uky.edu \\ Oluwaseun M. Akeyo \\ University of Kentucky, ochichikeyo@gmail.com \\ Dan M. Ionel \\ University of Kentucky, dan.ionel@uky.edu
}

Follow this and additional works at: https://uknowledge.uky.edu/peik_facpub

Part of the Power and Energy Commons

Right click to open a feedback form in a new tab to let us know how this document benefits you.

\section{Repository Citation}

Rallabandi, Vandana; Alawhali, Nasser; Akeyo, Oluwaseun M.; and Ionel, Dan M., "Simulation Studies for a Multi-MW Hybrid Wind-Solar PV System for Desalination Plants" (2018). Power and Energy Institute of Kentucky Faculty Publications. 30.

https://uknowledge.uky.edu/peik_facpub/30

This Conference Proceeding is brought to you for free and open access by the Power and Energy Institute of Kentucky at UKnowledge. It has been accepted for inclusion in Power and Energy Institute of Kentucky Faculty Publications by an authorized administrator of UKnowledge. For more information, please contact UKnowledge@lsv.uky.edu. 


\title{
Simulation Studies for a Multi-MW Hybrid Wind-Solar PV System for Desalination Plants
}

\author{
Digital Object Identifier (DOI) \\ https://doi.org/10.1109/ICRERA.2018.8566987
}

\section{Notes/Citation Information}

Published in 2018 7th International Conference on Renewable Energy Research and Applications (ICRERA).

(c) 2018 IEEE Copyright Notice. "Personal use of this material is permitted. Permission from IEEE must be obtained for all other uses, in any current or future media, including reprinting/republishing this material for advertising or promotional purposes, creating new collective works, for resale or redistribution to servers or lists, or reuse of any copyrighted component of this work in other works."

The document available for download is the authors' manuscript version that is accepted for publication. The final published version is copyrighted by IEEE and available as: V. Rallabandi, N. Alawhali, O. Akeyo, and D. M. Ionel, "Simulation Studies for a Multi-MW Hybrid Wind-Solar PV System for Desalination Plants," 2018 IEEE International Conference on Renewable Energy Research and Applications (ICRERA), Paris,2018, pp. 1413-1416. doi: 10.1109/ICRERA.2018.8566987 


\title{
Simulation Studies for a Multi-MW Hybrid Wind-Solar PV System for Desalination Plants
}

\author{
Vandana Rallabandi, Nasser Alawhali, Oluwaseun Akeyo and Dan M. Ionel \\ SPARK Laboratory, ECE Department, University of Kentucky, Lexington, KY \\ vandana.rallabandi@uky.edu,nasser.alawhali@uky.edu,m.akeyo@uky.edu,dan.ionel@uky.edu
}

\begin{abstract}
This paper presents a power system configuration and control schemes for a Multi-MW wind-solar hybrid system, which includes multiple wind turbines and solar panels to support a desalination plant. The wind and solar systems are sized such that the desalination plant obtains, as far as possible, its power from the renewable sources, to minimize the dependence on the utility grid. Each section of the wind turbine system includes a variable speed permanent magnet synchronous generator connected to the grid via a back-to-back voltage source converter. The rectifier operates the wind system at the maximum power point, and the inverter provides power to the desalination plant. The solar plant has multiple panels connected to the grid via a three phase converter, performing the dual functions of power transformation and maximum power point tracking. The modeling and validation of this system is performed with the PSCAD/EMTDC, a software typically employed for transient analysis.
\end{abstract}

Index Terms-Wind turbine, PV system, desalination plant, hybrid system, inverter, rectifier.

\section{INTRODUCTION}

Desalination plants powered by renewables can in principle be used to address some of the challenges arising from depleting water reserves around the world. This work studies the operation of a water desalination plant powered by hybrid wind and solar energy, which have been proven to be the renewable sources of energy with the least water consumption [1]. The work reported on hybrid systems ranges from sizing studies [2]-[4], power system configurations, power electronics topologies and control strategies [5]-[8]. Furthermore, energy management systems for a standalone wind powered desalination plant are discussed in [9].

The desalination plant studied in this paper is powered from hybrid sources with a wind system which includes multiple variable speed permanent magnet synchronous generators (PMSG), commerically available from, for example, [10]. The wind generators are connected to the desalination plant through a converter which includes a back-back connected active rectifier and inverter configuration. The active rectifier is controlled to operate the PMSG at speed which results in the extraction of maximum power from the wind. The advantages of using an active rectifier as opposed to a diode bridge include control over the currents of the generator, as well as the ability to operate the generator at the maximum torque per ampere condition.

The solar system includes mutliple panels interconnected with the load through an inverter which performs both the functions of maximum power point tracking and power conversion, as described in [11]. The hybrid wind-solar system feeds the desalination plant, and is capable of operating in both grid connected and standalone modes. In case of operation in the standalone mode, the wind system is operated in the constant power mode by controlling the speed of the rotor. Excess power may be either stored in a battery or dissipated in a resistor connected to the dc bus through a chopper. In the standalone mode, the solar system is only operated if the power from the wind is insufficient to meet the load demand.

\section{System Configuration and Operating Modes}

The desalination plant to be supplied is rated for $1 \mathrm{MW}$. At some times, the grid is unavailable and in these situations, the renewable sources should be capable of feeding the desalination plant. Due to the stochastic nature of wind speed variation, and because of the unpredictable nature of solar energy availability, it is not possible to guarantee that the load is completely supported by the renewable sources. In this regard, over-sizing the renewable sources would lead to a smaller loss of load probability, although the price to pay is higher installation costs and reduction in the plant's capacity factor. In this study, considering the site wind and solar data, the wind system is designed with 3-turbines, each rated for 2.1 MW, and the solar plant has a $3 \mathrm{MW}$ rating (Fig. 1).

Based on the power availability from different sources, the described hybrid desalination plant may be operated in different modes (Fig. 2). When a connection to the grid is available, the wind and solar side converters are controlled to extract the maximum power available from these renewable sources. The speed of the PMSG is controlled to operate the wind turbine at the tip-speed ratio that results in the maximum power coefficient.

Likewise, the solar side inverter maintains the PV array terminal voltage at the maximum power point value. In this situation, during periods of surplus power, when the load demand of the desalination plant operation is less than the total amount produced by the renewable sources, the grid absorbs the excess (Fig. 2a).

During periods when the power from the renewable sources is smaller than required by the desalination plant, the grid may be used to supply the balance power (Fig. 2b). It is worth noting that if the grid side inverters from both sources are not operating at their rated value, the residual capacity may be used to supply reactive power. 
The hybrid powered desalination plant may also be operated without grid connection, in the standalone mode, in which case, the renewable sources are curtailed such that they provide only the amount of power required (Fig. 2c). The output from the wind system may be maintained constant pitching the turbine's blade angles, such that a reduced fraction of the available wind energy is utilized. When there are multiple turbines, some may be entirely disconnected or their yaw set to a direction such that the rotational speed is smaller than the cut-in speed. The power from the solar PV system is curtailed by operating the arrays away from the maximum power point. In case, solar energy is not available, for example, during the night-time, the load may be supplied entirely from the wind system (Fig. 2d).

\section{System Modeling AND CONTROL}

Power electronics configurations and control schemes for wind energy systems have been studied in for example, [12]-[14]. In this study, the wind system is considered to be connected to the ac grid through back to back voltage source converters (Fig. 3). For each wind speed, there exists one angular speed at which the coefficient of power $\left(C_{p}\right)$ is maximized, as explained in the following example wind turbine model within PSCAD EMTDC,

$$
\begin{gathered}
P_{\text {mech }}=\frac{1}{2} \cdot \rho_{a} \cdot A \cdot C_{p} \cdot v_{w}^{3} \cdot \eta_{G B} \\
C_{p}=\left(\frac{4}{9}-\frac{\beta}{60}\right) \cdot \sin \left(20 \frac{\pi(\lambda-3)}{2(150-3 \beta)}\right)-\frac{2 \beta(\lambda-3)}{1087}
\end{gathered}
$$

where $P_{\text {mech }}$, represents the wind turbine mechanical power output; $\rho_{a}$, the air density; $A$, the rotor area; $C_{p}$, the power coefficient at zero degrees pitch angle; $v_{w}$, the wind speed; $\eta_{G B}$, the gearbox efficiency; $\beta$, the pitch angle, held at zero degrees for maximum power extraction, and $\lambda$, the tip speed ratio, which is the ratio of the blade tip to wind speed, $\lambda=$ $\frac{r w_{h}}{v_{w}}$, where, $w_{h}$ is the angular speed of the blade; $r$, its radius.

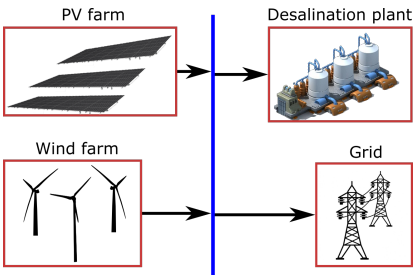

(a)

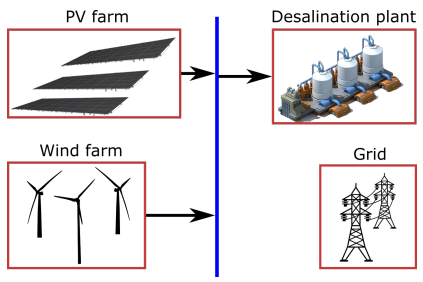

(c)

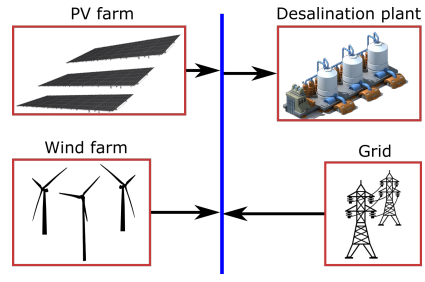

(b)

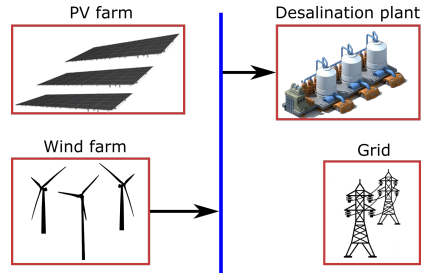

(d)
Fig. 2. Example operating modes for PV-wind hybrid system connected to a desalination plant.

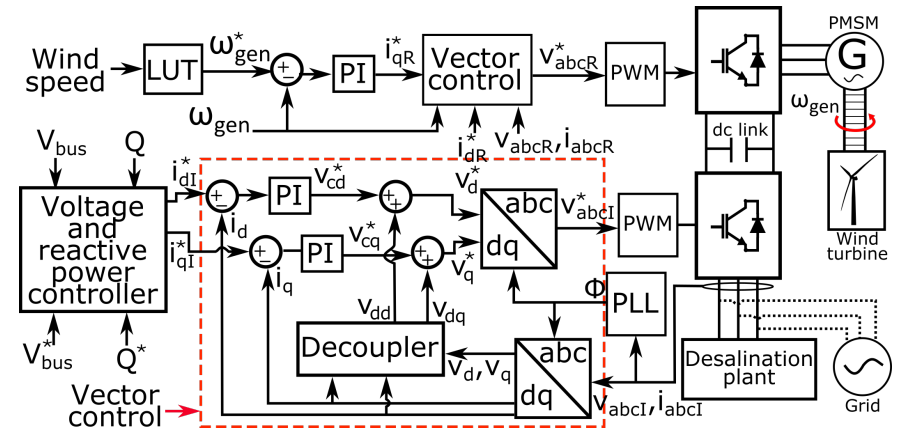

Fig. 3. Schematic diagram for the variable speed PMSG wind system with back-back voltage source converters. A lookup table (LUT) is used to determine the generator rotor speed corresponding to the desired operating point. In the grid connected and standalone modes, the inverter is controlled along grid voltage oriented and arbitrary reference frames respectively.
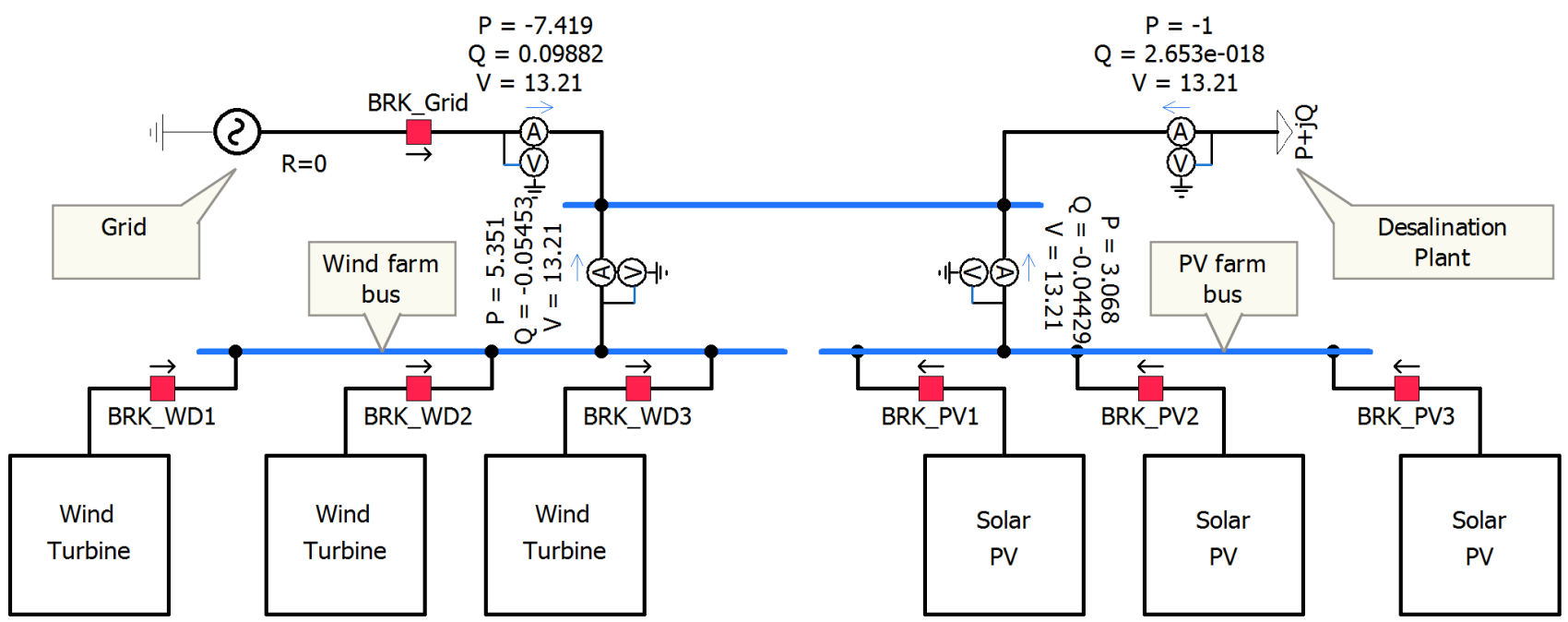

Fig. 1. Power circuit diagram in PSCAD/EMTDC software environment for an example Multi-MW wind and PV farm. The wind turbine and solar PV blocks are user defined subsystems, which houses all the components of each system. The desalination plant is represented by an R-L load. 
Maximum power point tracking involves the operation of the generator and therefore turbine at a rotational speed $w_{h}$ which would maximize $C_{p}$ and hence, the power extracted. The renewable side converter (RSC) is operated to control the speed of the generator such that the wind turbine operates at the optimum tip speed ratio for each wind speed. A look up table defines the relation between the angular velocity corresponding to the maximum power point, and wind speed. The inverter control ensures system power balance by holding the dc bus voltage constant.

The renewable side converter (RSC) for the wind system is controlled in a reference frame oriented along the rotor daxis to ensure maximum torque per ampere for the generator, and an encoder on the shaft imparts information about the rotor's position, although sensorless control schemes may also be used. The RSC operates the generator at the speed which leads to the extraction of maximum power from the wind. Outer speed and inner current control loops are employed for the RSC.

The inverter is controlled using the grid voltage phase angle for the transformations obtained from a phase locked loop (PLL). In this study, the reference active current component, $i_{d I}$ is regulated to maintain the dc link voltage at $1.1 \mathrm{kV}$. During periods of low wind power availability, the RSC can be used to provide reactive power to the grid, although it is maintained at zero here.

The solar panels in each section of the plant are considered to be directly connected to the dc-link of their three phase inverters, which are controlled to operate the system at the maximum power point at different conditions of irradiance. The solar inverter, which performs both functions of maximum power point tracking and power interfacing, is also controlled along a reference frame oriented with the grid voltages. The dc bus voltage reference is obtained from a maximum power point controller, and it is maintained at this value through outer voltage and inner current loops.

When the grid is unavailable, the system is controlled to operate in the standalone mode. The RSC is controlled in this situation to ensure operation of the wind turbines in the constant power region. Constant power operation may be obtained by pitching, i.e. modifying $\beta$, referring to (2). Excess power, which may occur due to gusts of wind, is absorbed by a resistor connected to the dc bus through a dc-dc converter. The solar system is only operated if the power from the wind generators is insufficient to meet the load.

In the standalone mode, the inverters for the solar and the wind systems are controlled along an arbitrary reference frame rotating at the desired angular velocity, in this case $60 \mathrm{~Hz}$. The active and reactive powers are given by,

$$
P=\frac{3}{2}\left(v_{d} i_{d I}\right), \quad Q=\frac{3}{2}\left(v_{q} i_{d I}\right) .
$$

Where, $v_{d}$ and $v_{q}$ are the $d-$ and $q-$ axes voltages respectively, and $i_{d I}$, the $d$-axis component of the load current. The amount of active power supplied is thus controlled by the current reference, $i_{d I}^{*}$. The value of this current command is derived from an outer dc bus voltage controller, and $i_{q I}^{*}$ is maintained at zero, for orientation along the arbitrary synchronously rotating reference frame. The reactive power demand depends on the load, in the standalone mode.

\section{Simulation Studies and Results}

In order to validate the controls and configuration of the hybrid wind and solar PV system, a system model subjected to multiple transient conditions was developed in PSCAD/EMTDC environment. This model includes three 2.1 MW wind turbines, a $3 \mathrm{MW}$ solar PV system, and a $1 \mathrm{MW}$ desalination plant all connected to the grid represented as a $13.2 \mathrm{kV}$ voltage source.

The wind system for this study includes three identical sections, each with a 2.1 MW wind turbine coupled to a PMG, whose terminals are connected to the grid via a back to back voltage source converter and transformer. At $7 \mathrm{~s}$ simulation time, the wind speed is suddenly reduced from $9.5 \mathrm{~m} / \mathrm{s}$ to $7.5 \mathrm{~m} / \mathrm{s}$ leading to a decrease in the generator's mechanical power input. In order to maintain the generator rotor speed at its new MPPT reference, the outer speed controller varies the active component of current, $i_{q R}$, such that the generator's electrical power output reduces (Fig. 4b).

The reduction in wind speed also leads to a decrease in the dc link voltage due to a transient power imbalance. The dc voltage controller regulates the load side active current command $i_{d I}$, such the inverter's real power output corresponds to the value required to maintain the bus voltage at its $1.1 \mathrm{kV}$ reference value, and accordingly, steady state is attained (Fig. 4c).

The PV array irradiance is varied from $714 \mathrm{~W} / \mathrm{m}^{2}$ to $350 \mathrm{~W} / \mathrm{m}^{2}$ and then zero at $10 \mathrm{~s}$ and $15 \mathrm{~s}$ simulation time, respectively to represent the transition from midday to late night. At 10s simulation time, this leads to a transient reduction in the PV array terminal voltage (Fig. 4d), the dc bus voltage controller regulates the real power output of the inverter such that the array terminal voltage $\left(v_{p v}\right)$ corresponds to its MPPT reference $\left(v_{M P P T}\right)$.

At 20s simulation time, the grid becomes unavailable and the desalination plant is exclusively powered by wind energy in the standalone mode to illustrate a nighttime condition, when the energy from the solar PV system is unavailable. In this study, one of the wind turbine sections is disconnected, while the remaining operate in the constant power mode in order to supply the amount of power required by the desalination plant. The position information for the transformations is obtained from a reference frame synchronously rotating at $60 \mathrm{~Hz}$ (Figs. 4e, 4f).

\section{CONCLUSION}

This paper presents a solution for operating a multi-MW rated water desalination plant with the combined use of wind and PV sources. This configuration, with hybrid renewable sources having staggered availabilities, allows the system to operate with minimum dependence on the grid. 


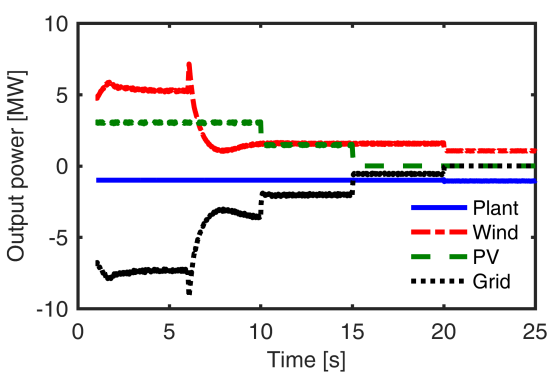

(a)

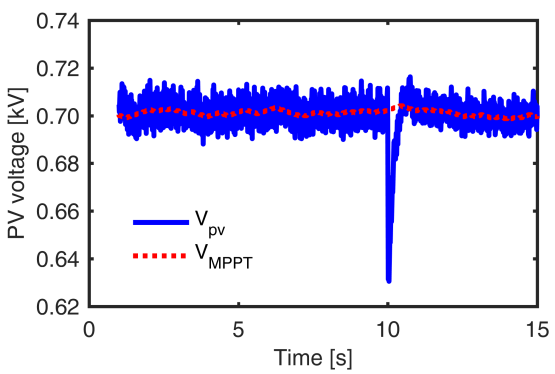

(d)

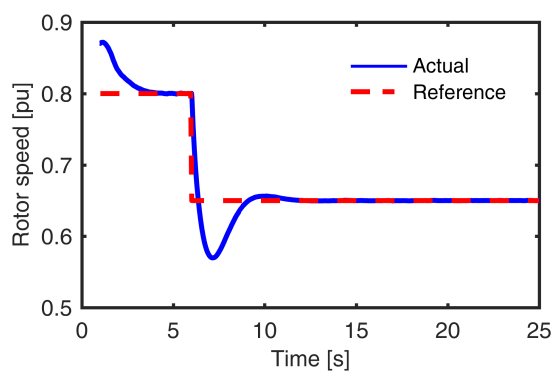

(b)

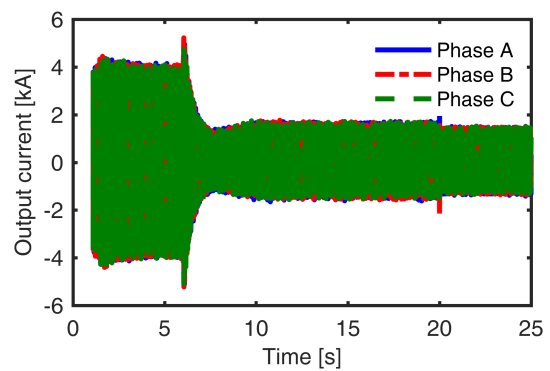

(e)

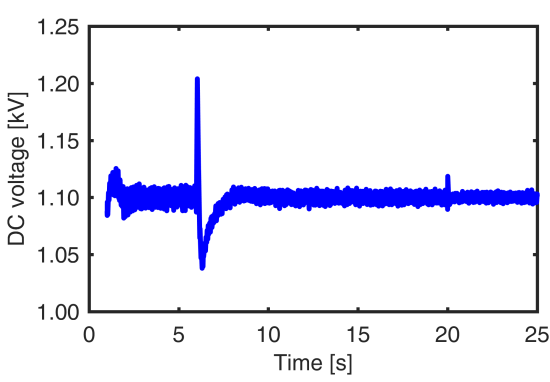

(c)

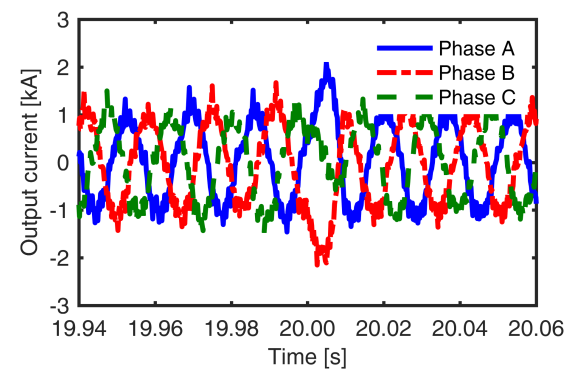

(f)

Fig. 4. Simulation study for validating hybrid system control during a transient wind and irradiance change at $7 \mathrm{~s}$ and $10 \mathrm{~s}$ simulation times, respectively. After the irradiance level goes to zero at $15 \mathrm{~s}$, the grid is disconnected at $20 \mathrm{~s}$ and the wind power is maintained constant such that the load of the desalination plant is met. The results show: The real power (a), generator rotor speed and MTPA reference (b), wind system dc link voltage (c), the PV array voltage and MPPT reference (d), the wind turbine current (e), zoomed-in wind generator output current, emphasizing the transition from grid connected to stand alone mode (f).

The renewable sources are over-sized so that the desalination plant can operate even during periods of low wind speed and solar irradiance. The system is capable of operation in both grid connected and standalone modes, and further, reactive power support can be provided during periods of low renewable power availability. The simulation of the system under different operating conditions including extreme cases of wind and irradiance variations, as well as grid connected and standalone modes were conducted in PSCAD/EMTDC.

\section{ACKNOWLEDGMENT}

The support of University of Kentucky, the L. Stanley Pigman endowment, and of the SPARK Laboratory, Power and Energy Institute of Kentucky (PEIK), is gratefully acknowledged.

\section{REFERENCES}

[1] F. Blaabjerg and D. M. Ionel, Renewable Energy Devices and Systems with Simulations in MATLAB and ANSYS, CRC Press, Boca Raton, FL, 2017.

[2] M. Alsayed, M. Cacciato, G. Scarcella, and G. Scelba, "Multicriteria optimal sizing of photovoltaic-wind turbine grid connected systems," IEEE Transactions on Energy Conversion, vol. 28, no. 2, pp. 370-379, June 2013.

[3] U. Akram, M. Khalid, and S. Shafiq, "Optimal sizing of a wind/solar/battery hybrid grid-connected microgrid system," IET Renewable Power Generation, vol. 12, no. 1, pp. 72-80, 2018.

[4] C. Andalib-Bin-Karim, X. Liang, and H. A. Chowdhury, "Generation reliability assessment of stand-alone hybrid power system a case study," in 2017 IEEE International Conference on Industrial Technology (ICIT), March 2017, pp. 434-439.
[5] S. Bae and A. Kwasinski, "Dynamic modeling and operation strategy for a microgrid with wind and photovoltaic resources," IEEE Transactions on Smart Grid, vol. 3, no. 4, pp. 1867-1876, Dec 2012.

[6] R. G. Wandhare and V. Agarwal, "Novel integration of a pv-wind energy system with enhanced efficiency," IEEE Transactions on Power Electronics, vol. 30, no. 7, pp. 3638-3649, July 2015.

[7] S. K. Tiwari, B. Singh, and P. K. Goel, "Design and control of microgrid fed by renewable energy generating sources," in 2016 IEEE 6th International Conference on Power Systems (ICPS), March 2016, pp. $1-6$.

[8] J. Hui, A. Bakhshai, and P. K. Jain, "A hybrid wind-solar energy system: A new rectifier stage topology," in 2010 Twenty-Fifth Annual IEEE Applied Power Electronics Conference and Exposition (APEC), Feb 2010, pp. 155-161.

[9] L. Guo, W. Liu, X. Li, Y. Liu, B. Jiao, W. Wang, C. Wang, and F. Li, "Energy management system for stand-alone wind-powered-desalination microgrid," IEEE Transactions on Smart Grid, vol. 7, no. 2, pp. 10791087, March 2016.

[10] "Vestas V116-2.1MW" https://www.vestas.com/en/products/turbines/ v116-2_2_mw, accessed: 2018-08-05.

[11] V. Rallabandi, O. M. Akeyo, and D. M. Ionel, "Modeling of a multimegawatt grid connected pv system with integrated batteries," in 2016 IEEE International Conference on Renewable Energy Research and Applications (ICRERA), Nov 2016, pp. 1146-1151.

[12] R. Teodorescu and F. Blaabjerg, "Flexible control of small wind turbines with grid failure detection operating in stand-alone and grid-connected mode," IEEE Transactions on Power Electronics, vol. 19, no. 5, pp. 1323-1332, Sept 2004.

[13] M. E. Haque, K. M. Muttaqi, and M. Negnevitsky, "Control of a stand alone variable speed wind turbine with a permanent magnet synchronous generator," in 2008 IEEE Power and Energy Society General Meeting Conversion and Delivery of Electrical Energy in the 21st Century, July 2008, pp. 1-9.

[14] T. Hirose and H. Matsuo, "Standalone hybrid wind-solar power generation system applying dump power control without dump load," IEEE Transactions on Industrial Electronics, vol. 59, no. 2, pp. 988-997, Feb 2012. 